\title{
PENGARUH PENERAPAN TUTORIAL PADA MATA KULIAH ASUHAN PERSALINAN DAN BAYI BARU LAHIR TERHADAP PARTISIPASI DAN MOTIVASI BELAJAR MAHASISWI D III KEBIDANAN SEMESTER 3
}

\author{
Sinar Pertiwi ${ }^{1}$, Ana Iriana ${ }^{2}$ \\ 1, 2, Dosen Jurusan Kebidanan Poltekkes Kemenkes Tasikmalaya
}

\begin{abstract}
ABSTRAK
Metoda pembelajaran tutorial mampu memberikan wadah untuk peningkatan motivasi dan partisipasi mahasiswi dalam proses pembelajaran. Tujuan penelitian ini untuk menganalisa Pengaruh Penerapan Tutorial Mata Kuliah Asuhan Persalinan Terhadap Partisipasi dan Motivasi Belajar Mahasiswi D III Kebidanan Semester 3 Tahun 2015. Penelitian ini menggunakan metoda quasi eksperiman dengan rancangan penelitian non equivalent control group design. Populasi penelitian adalah seluruh mahasiswa D III kebidanan semester III tahun akademik 2015/2016 sejumlah 114 mahasiswa dari wilayah Tasikmalaya dan Cirebon. Random sampling digunakan untuk penetapan jumlah sample baik pada kelompok perlakuan maupun kontrol sejumlah 30 orang per kelompok. Data penelitian diambil menggunakan kuesioner dan lembar observasi. Uji keseragaman starting point dan uji pengaruh digunakan uji chi-square sedangkan untuk uji perbedaan pretest dan post test (motivasi dan partisipasi) menggunakan uji Mc-Nemar. Hasil penelitian Terdapat perbedaan motivasi dan partisipasi dari kelompok kontrol dan perlakuan dengan $p$-value < 0,05 (motivasi $p=0,001$ dan partisipasi $p=0,01$ dan $p=0,04$ ), Terdapat pengaruh pemberian tutorial terhadap partisipasi mahasiswa dengan $p$-value $<0,05$ (Klp. $1 p=0,004$ dan $p=0,002$; Klp.2 $p=0,012$ dan Klp.3 $p=0,012$ serta $p=0,001$ ). Tidak ada pengaruh pemberian tutorial terhadap motivasi mahasiswa dengn $p$-value $>0,05 p=0,453$. Saran ke depan proses pelaksanaan tutorial dievaluasi kembali agar faktor motivasi peserta lebih meningkat.
\end{abstract}

Kata Kunci : Tutorial, Partisipasi, Motivasi Belajar.

\begin{abstract}
Tutorial learning method can provide a container for increased motivation and student participation in the learning process. The purpose of this study was to analyze the Influence Application Tutorial On Delivery Care Course Against Participation and Motivation Student $D$ III Midwifery Semester 3 Year 2015. This study used a quasi-experimental method to the study design Nonequivalent Control Group Design. The study population was all students DIII midwifery third semester of the academic year 2015/2016 a number of 114 students from Tasikmalaya and Cirebon. Random sampling was used for the determination of the amount of sample both the treatment group and a control group of 30 people per group. The research data taken using instruments such as questionair and observation. Uniformity test starting point and test the effect of chi-square test was used to test differences while pretest and post test (motivation and participation) using Mc Nemar test. There are differences in the results of the study of motivation and participation of control and treatment groups with $p$ value $<0.05(p=0.001$ motivation and participation $p=0.01$ and $p=0.04)$, There is a tutorial giving effect to the participation of students with $p$ value $<0.05$ (Klp.1 $p=0.004$ and $p=0.002$; $p=0.012 \mathrm{~K} / \mathrm{p} .2$ and Klp.3., $p=0.012$ and $p=0.001$ ). No effect of a tutorial on student motivation dengn $p$-value $>0.05, p=0.453$. It is suggested taht The implementation process tutorial re-evaluated in order to increase student's motivation.
\end{abstract}

Keyword : Tutorial, Participation, Motivation 


\section{PENDAHULUAN}

Pendidikan mempunyai peran yang menentukan bagi perkembangan dan perwujudan dari individu serta pembangunan kualitas Sumber Daya Manusia suatu bangsa (Setyosari, 2012). Tenaga Bidan yang berkualitas dihasilkan oleh Institusi pendidikan Kebidanan yang dikelola dengan memperhatikan perkembangan ilmu pengetahuan, teknologi dan regulasi (Kemenkes RI, 2014).

Peningkatan mutu pendidikan harus dilakukan secara menyeluruh melalui kegiatan belajar mengajar yang meliputi aspek kognitif, afektif dan psikomotor. Pendidikan Bidan di Indonesia saat ini mayoritas berada pada jenjang D III kebidanan dengan kualifikasi sebagai bidan pelaksana, yang memiliki kompetensi untuk melaksanakan praktiknya baik di Institusi pelayanan maupun di praktik perorangan (Kemenkes RI, 2010).

Profil lulusan D III kebidanan adalah seorang lulusan ahli madya kebidanan yang mampu berperan sebagai pemberi asuhan, penggerak masyarakat, komunikator dan pengelola. Profil lulusan tersebut membutuhkan suatu kurikulum berbasis kompetensi dan penerapan proses belajar mengajar yang mampu mendorong dan menjadikan mahasiswa bersikap peka, kritis, mandiri, kreatif dan bertanggung jawab (Sudjamiko dkk, 2003). Dengan telah diberlakukannya kurikulum D III Kebidanan yang berbasis kompetensi pada tahun 2010, maka metoda pembelajaran Problem Based Learning sudah diperkenalkan.

Perbedaan signifikan antara metoda klasikal dan PBL adalah pada proporsi kemandirian mahasiswa lebih menonjol pada PBL. Tugas utama mahasiswa adalah menjadikan belajar sebagai proses pengembangan diri untuk dapat mandiri dan berpartisipasi dalam dunia kerja, maka kegiatan belajar yang dialami mahasiswa di lembaga pendidikan harus bersifat aktif dengan ciri, partisipasi, kemandirian dan motivasi belajar mahasiswa tinggi. (Wardani, 2012). Salah satu metoda pembelajaran PBL

\section{METODE PENELITIAN}

Penelitian ini menggunakan metoda quasi eksperiman dengan rancangan penelitian nonequivalent control group design. Ada tiga hal yang menjadi karakteristik penelitian eksperimen (Dahlan, 2011) yaitu; adalah tutorial. Proses tutorial yang ideal adalah proses tutorial yang memberi penekanan pada pembentukan pengalaman belajar mahasiswa, yang mengaktifkan mahasiswa untuk berinteraksi dengan sumber-sumber belajar, serta yang memberi kesempatan kepada mahasiswa untuk saling bekerja sama dalam membangun pengetahuan dan memperoleh makna dari apa yang dipelajari.

Menurut Julaeha (2002) menemukan bahwa mayoritas mahasiswa lebih suka belajar sendiri, tidak terlalu teratur dan santai. Disamping itu, pada kegiatan tutorial ditemukan bahwa tidak sampai seperlima mahasiswa yang memanfaatkan kegiatan tutorial. Berdasarkan hasil penelitian tersebut, dikatakan bahwa proses tutorial yang dilaksanakan belum menunjukkan kondisi yang diharapkan. Keterlibatan mahasiswa untuk aktif dalam proses tutorial masih belum menunjukkan gejala yang menggembirakan.

Program Studi DIII Kebidanan Tasikmalaya, telah menerapkan metoda pembelajaran tutorial sejak tahun 2013, khususnya pada mata kuliah Asuhan Kebidanan. Hal ini membutuhkan kemandirian, penguasaan materi dan skill yang kompeten, motivasi dan partisipasi tinggi mahasiswa pada saat proses belajar mengajarnya.

Berdasarkan hasil studi pendahuluan yang dilakukan oleh peneliti pada saat menjadi tutor sejak di berlakukan penerapan tutorial ditemukan hasil observasi, rata-rata 4 dari 10 mahasiswa per tim tutorial memiliki keaktifan lebih dari $80 \%$ dalam mengemukakan pendapat.

Tujuan penelitian ini adalah untuk menganalisa pengaruh penerapan tutorial mata kuliah asuhan persalinan terhadap partisipasi dan motivasi belajar mahasiswi DIII Kebidanan semester 3 tahun 2015. Hipotesa penelitian: ( $\mathrm{Ha})$ ada pengaruh penerapan tutorial mata kuliah asuhan persalinan terhadap partisipasi dan motivasi belajar mahasiswi.

memanipulasi, mengontrol variabel dan melakukan observasi. Dalam penelitian ini, menempatkan subjek penelitian ke dalam dua kelompok yang terdiri dari kelompok eksperimen dan kelompok kontrol. 
Populasi dalam penelitian ini adalah seluruh mahasiswi D III Kebidanan semester 3 Tahun akademik 2015/2016 sejumlah 114 orang. Pengambilan sample dilakukan secara simple random sampling untuk mendapatkan 30 orang pada kelompok kontrol dan 30 orang pada kelompok perlakuan. 30 orang $D$ III wilayah Tasikmalaya menjadi kelompok perlakuan dan 30 orang D III wilayah Cirebon menjadi kelompok kontrol. Mahasiswa semester 3 wilayah Tasikmalaya dan Cirebon sebelumnya mendapatkan mata kuliah dengan mayoritas metoda pembelajaran Klasikal berupa CTJ, Seminar dan Penugasan hanya 1 mata kuliah Askeb 1 yang telah menerapkan metoda Tutorial. Pada Semester 3 semua pembelajaran Asuhan Kebidanan memuat Metoda PBL Tutorial untuk wilayah Tasikmalaya sedangkan Untuk wilayah Cirebon masih menggunakan metoda klasikal.

Penelitian dilakukan di Ruang Kelas Tk 1 dan Laboratorium Jurusan Kebidanan Tasikmalaya sejumlah 3 ruangan dan ruang kelas Prodi Cirebon sejumlah 1 ruangan (kelas kemuning). Waktu pelaksanaan pada bulan September sesuai dengan jadwal 2 siklus tutorial yang ditetapkan yaitu pada topik penyulit dan komplikasi persalinan kala I dan II serta dan topik penyulit dan komplikasi persalinan kala III dan IV.

\section{HASIL DAN PEMBAHASAN}

Penelitian dilakukan bulan Oktober tahun 2015 terhadap kelompok perlakuan dan keterlibatan 3 enumerator yaitu 3 orang tutor di kelompok perlakuan (masing-masing kelompok 10 orang) dan 2 orang lecture di
Instrumen penelitian yang digunakan adalah lembar questionair dan lembar observasi. Kuesioner untuk mengumpulkan data motivasi belajar mahasiswa menggunakan kuesioner motivasi belajar dari hasil penelitian Dwi Ernawati yang diujikan pada Mahasiswa Semester 3 DIII Kebidanan Tasikmalaya pada 20 orang. Hasil uji Reliabilitas instrumen motivasi dengan Alpha cronbach adalah 0,726 artinya jika alpha antara $0,70-0,90$ maka reliabilitas tinggi.

Penilaian partisipasi belajar mahasiswa menggunakan lembar observasi yang dicobakan pada sesi tutorial di semester 3 pada mata kuliah metoda tutorial, khususnya untuk uji ICC dari tim tutor MK asuhan persalinan dan Bayi Baru Lahir sejumlah 7 orang. Hasil uji Intra class coeficient corelation 0,662 yang berarti hasil tes dapat dipercaya. Hal ini sesuai dengan kriteria ICC bahwa jika nilai ICC $\leq 0,6$ (tes tidak dapat dipercaya), ICC $=0,6$ (tes dapat dipercaya), $I C C \geq 0,6$ (tes dapat dipercaya). Oleh Karena ICC hasil validasi $\geq 0,6$ maka hasil tes rater dapat dipercaya.

Analisis dilakukan untuk mengetahui distribusi frekuensi, mean, median, modus dan SD. Uji starting point digunakan uji chisquare sedangkan untuk uji perbedaan pretest dan post test (motivasi dan partisipasi) dengan menggunakan uji Mc-Nemar.

kelompok kontrol. Hasil penelitian tentang pengaruh metoda tutorial terhadap partisipasi dan motivasi belajar mahasiswa didapatkan sebagai berikut :

Tabel 1. Hasil Nilai Starting Point Untuk Variabel Partisipasi Kelompok Kontrol dan Perlakuan

\begin{tabular}{cc}
\hline & $\begin{array}{c}\text { Hasil uji Fisher exact } \\
\text { Asymp (2-sided) }\end{array}$ \\
\hline Kelompok 1 & 0,04 \\
\hline Kelompok 2 & 0,01 \\
\hline Kelompok 3 & 0,01 \\
\hline
\end{tabular}

Hasil Tabel 1. Karena $p$-value $<0,05$ maka Ho ditolak: ada perbedaan starting point antara kelompok kontrol dan perlakuan 
Sinar Pertiwi, Ana Iriana, Poltekkes Tasikmalaya; Tutorial, Partisipasi, Motivasi Belajar.

Tabel 2. Hasil Nilai Starting Point Untuk Variabel Motivasi

\begin{tabular}{cc}
\hline Kelompok CTJ dan Tutorial & $\begin{array}{c}\text { Hasil uji Chi-Square } \\
\text { Asymp (2-sided) }\end{array}$ \\
\hline Co, & 001 \\
\hline
\end{tabular}

Hasil Tabel 15. Karena $\mathrm{p}$ value $<0,05$ maka Ho ditolak: ada perbedaan starting point untuk motivasi antara kelompok kontrol dan perlakuan.

Tabel 3. Pengaruh Metoda Pembelajaran Terhadap Partisipasi Mahasiswa

\begin{tabular}{clc}
\hline \multirow{2}{*}{ CTJ } & \multicolumn{1}{c}{ Metoda } & p-value \\
\hline \multirow{2}{*}{ Tutorial } & Kuantitas & 1,000 \\
\cline { 2 - 3 } & Kualitas & 1,000 \\
\cline { 2 - 3 } & Klp 1 Kuantitas & 0,004 \\
\cline { 2 - 3 } & Klp 1 Kualitas & 0,002 \\
\cline { 2 - 3 } & Klp 2 Kuantitas & 0,012 \\
\cline { 2 - 3 } & Klp 2 Kualitas & 0,012 \\
\cline { 2 - 3 } & Klp 3 Kuantitas & 0,012 \\
\hline
\end{tabular}

Dari tabel di atas diketahui $p$-value uji Mc-Nemar pada kelompok kontrol sebesar 1,00 dan $1,00(>0,05)$ maka hipotesis nol $(\mathrm{Ho})$ diterima yang artinya tidak ada perubahan yang signifikan partisipasi mahasiswa pada kelompok kontrol secara kualitas dan kuantitas.

Hasil uji menunjukan nilai test statistic kelompok perlakuan 1 diketahui $p$-value uji Mc-Nemar masing-masing sebesar 0,004 dan $0,002(<0,05)$ maka tolak $H_{0}{ }^{\prime}$ artinya ada perubahan yang signifikan partisipasi setelah menggunakan metoda pembelajaran tutorial pada kelompok 1.
Hasil uji menunjukan nilai test statistic kelompok perlakuan 2 diketahui $p$-value uji Mc-Nemar masing-masing sebesar 0,012 $(<0,05)$ maka tolak $\mathrm{H}_{0}$, artinya ada perubahan yang signifikan partisipasi setelah menggunakan metoda pembelajaran tutorial pada kelompok 2 .

Hasil uji menunjukan nilai test statistic kelompok perlakuan 3 diketahui $p$-value uji Mc-Nemar masing-masing sebesar 0,012 dan $0,001(<0,05)$ maka tolak $\mathrm{H}_{0}$ yang artinya ada perubahan yang signifikan partisipasi setelah menggunakan metoda pembelajaran tutorial pada kelompok 3.

Tabel 4. Pengaruh Metoda Pembelajaran Terhadap Motivasi Mahasiswa

\begin{tabular}{cc}
\hline Metoda & p-value \\
\hline CTJ & 1,000 \\
\hline Tutorial & 0,543
\end{tabular}

Dari tabel di atas diketahui $p$-value uji Mc-Nemar sebesar 0,453 $(>0,05)$ maka $\mathrm{H}_{0}$ diterima artinya tidak ada perubahan yang signifikan motivasi mahasiswa sesudah diberikan metoda pembelajaran tutorial.
Sedangkan hasil uji Mc-Nemar diperoleh nilai p-value 1,000 $(>0,05)$ maka Ho diterima yang artinya tidak ada perubahan yang signifikan motivasi mahasiswa sesudah diberikan metoda pembelajaran CTJ. 


\section{PEMBAHASAN}

Pada penelitian ini terdapat keterbatasan dalam menyamakan starting point secara analitik karena hasil nilai partisipasi dan motivasi kelompok kontrol dan perlakuan masih terdapat perbedaan. Hanya peneliti telah melakukan penyamaan starting point dari klasifikasi sama level semester III yang diteliti dan Prodinya sama-sama D III Kebidanan walaupun yang satu di Cirebon dan Tasikmalaya mengingat kebutuhan metoda pembelajaran klasikal dan tutorial.

Hasil penelitian pada kelompok kontrol baik partisipasi secara kuantitatif dan kualitatif $71 \%$ pada kategori sedikit dan kurang. Hal ini sejalan dengan teori bahwa pembelajaran klasikal umumnya dalam proses pembelajaran mahasiswa bersikap pasif dalam mengikuti kuliah, mereka baru aktif jika diberikan tugas atau disuruh oleh dosen. Metode pembelajaran yang digunakan umumnya ceramah dan diskusi serta pemberian tugas. Oleh sebab itu, untuk menciptakan proses pembelajaran yang partisipatif aktif diperlukan adanya pendekatan dan metode pembelajaran yang sesuai (Sumarsono, 2009).

Hasil penelitian terjadi peningkatan partisipasi baik dari kategori kuantitas dan kualitas pada kelompok perlakuan. Dengan menerapkan teknik pembelajaran aktif seperti tutorial tersebut serta memberi penekanan pada upaya pelibatan aktif mahasiswa maka partisipasi mahasiswa dalam proses tutorial serta hasil belajar mahasiswa akan meningkat (Widuroyekti, 2006).

Perlu diingat untuk mengoptimalkan hasil partisipasi mahasiswa dalam proses tutorial maka perlu dilaksanakan proses tutorial yang ideal yaitu proses tutorial yang memberi penekanan pada pembentukan pengalaman belajar mahasiswa, yang mengaktifkan mahasiswa untuk berinteraksi dengan sumber-sumber belajar, serta yang memberi kesempatan kepada mahasiswa untuk saling bekerja sama dalam membangun pengetahuan dan memperoleh makna dari apa yang dipelajari.

Pengajaran klasikal biasanya dilakukan pada 30-40 mahasiswa di dalam sebuah ruangan. Dalam kondisi seperti ini, kondisi belajar mahasiswa secara individual baik menyangkut kecepan belajar, kesulitan belajar dan minat belajar sukar untuk diperhatikan oleh dosen. Banyaknya materi yang akan diajarkan, urutan materi pelajaran, kecepatan guru mengajar dan lain-lain sepenuhnya ada ditangan Dosen (Oviyanti, 2009).

Tutorial adalah kunci keberhasilan metode PBL. Tutorial yang efektif akan menjamin pencapaian tujuan belajar. Pada tutorial yang efektif, diskusi kelompok beriangsung secara kooperatif dan bukarmya secara kompetitif. Setiap mahasiswa harus berpartisipasi aktif, sebaliknya anggota kelompok yang dominan diminta untuk mengurangi dominasinya. Partisipasi mahasiswa dalam proses tutorial dapat dipengaruhi oleh beberapa faktor, antara lain karakteristik mahasiswa tersebut, kualitas skenario yang digunakan dan peranan tutor sebagai fasilitator. Apabila partisipasi mahasiswa dalam proses tutorial kurang, maka tutorial tidak akan efektif sehingga tujuan pembelajaran akan sulit dicapai (Hamidy 2009). Dalam hal ini metoda pembelajaran tutorial memang dikondisikan dan diatur agar mahasiswa lebih berpartisipasi melalui pembagian tugas dalam menerapkan 7 jumps. Dengan tingkat partisipasi yang baik tentunya kemandirian mahasiswa akan meningkat.

Hasil penelitian ini tidak sama dengan hasil penelitian (Jatiro, 2013) yang menunjukan adanya hubungan antara PBL salah satunya tutorial dapat meningkatkan motivasi belajar siswa. Beberapa faktor yang dapat meningkatkan proses independent study mahasiswa pada sesi tutorial adalah motivasi, kemampuan mahasiswa dalam mencari informasi, dan cara mahasiswa dalam belajar serta kemampuan mahasiswa dalam manajemen waktu. Motivasi belajar adalah kekuatan yang menyebabkan mahasiswa terlibat dalam suatu proses pembelajaran, fokus pada tujuan belajar dan mengerjakan tugas belajar. Motivasi dapat bersifat ekstrinsik maupun intrinsik. Apabila 
mahasiswa memiliki motivasi yang baik terutama motivasi intrinsik maka tujuan proses independent study akan terlaksana dengan baik. Oleh karena itu perlu diberikan suatu feedback yang positif terhadap apa yang telah dilakukan mahasiswa dalam proses belajar mandirinya, dan perlu dilakukan suatu penilaian yang jelas sehingga dapat meningkatkan motivasi belajar bagi mahasiswa (Wahyura, Aryanty, Elrifda, 2013).

$$
\text { Pada penelitian ini perlu }
$$

dipertimbangkan akan faktor eksternal yang

\section{KESIMPULAN}

Terdapat perbedaan motivasi dan partisipasi dari kelompok kontrol dan perlakuan. Terdapat pengaruh pemberian tutorial terhadap partisipasi mahasiswa. Tidak ada pengaruh pemberian tutorial terhadap motivasi mahasiswa.

Saran yang disampaikan pada proses pelaksanaan tutorial di Poltekkes Kemenkes

\section{DAFTAR PUSTAKA}

Barokah W (2006). Pendekatan belajar aktif dan peningkatan partisipasi mahasiswa dalam proses tutorial tatap muka. Jurnal Pendidikan, Voume. 7, Nomor 1.

Dahlan S.M, (2011). Statistik untuk kedokteran dan kesehatan: deskriptif, bivariat, dan multivariat. Edisi 5. Jakarta: Salemba Medika.

Fitri O, (2009). Pengelolaan pengajaran. Palembang: Rafah Press, HIm. 19

Hadi S, (2009). Pengembangan model pembelajaran terpusat pada mahasiswa (student centered) dan besifat Contextual Teaching And Learning. JPE-Volume 2, Nomor 1.

Hamidy \& Yulis, (2009). Faktor-faktor yang mempengaruhi partisipasi mahasiswa dalam proses tutorial pada metode belajar Problem-Based Learning di Fakultas Kedokteran Universitas Riau, Universitas Riau.

Julaeha S, (2002). Memahami gaya dan strategi belajar mahasiswa. Jurnal Pendidikan Terbuka dan Jarak Jauh, Vol dapat mengurangi motivasi belajar seperti kurang memadainya upaya motivasi dari dosen sendiri dan faktor eksternal seperti sarana prasarana penunjang pembelajaran sehingga baik metoda klasik dan PBL dapat berjalan dengan efektif. Selain itu, jangan melaksanakan PBL tutorial seperti suatu prosedural saja tanpa ada evaluasi dan feedback sehingga manfaatnya tidak dapat dicapai dengan maksimal.

Tasikmalaya perlu dievaluasi kembali agar faktor yang dapat meningkatkan motivasi pembelajaran dapat di optimalisir. Faktor eksternal seperti sarana dan prasarana serta motivasi dari tutor di Poltekkes Kemenkes Tasikmalaya dapat ditingkatkan sehingga kemandirian mahasiswa sebagai hasil dari pembelajaran tutorial dapat dicapai.

3 (2). Jakarta: Pusat Studi Indonesia, Universitas Terbuka.

Kemenkes RI (2014). Draf Kurikulum D III Kebidanan Revisi 2014. Jakarta Kemenkes RI.

Kemenkes RI 2010, Kurikulum Inti D III Kebidanan HK 02.05/I/III/2/08794/2011. Jakarta. Kemenkes RI.

Sudjatmiko (2003). Kurikulum Berbasis Kompetensi. Jakarta: Dirjen Pendidikan Dasar dan Menengah Direktorat Tenaga Kependidikan

Wardani (2012). Studi komparatif hasil belajar menggunkan metoda kooperatif dengan metoda ceramah di jurusan elektronika industri SMK Negeri 26 Jakarta pada mata pelajaran teknik digital. Jakarta. Universitas Negeri Jakarta.

Wely W, Nindya A, Solha E., (2013). Performa independent study mahasiswa blok urogenitalia dalam tutorial PSPD FKIK UNJA. Program Studi Pendidikan Dokter, Fakultas Kedokteran dan IImu Kesehatan Universitas Jambi. 